\title{
Awareness and Its Associated Factors of Obstetrics Fistula among Antenatal Care Attendees in Injibara Town Health Institutions, Awi Zone, North West, Ethiopia, 2019
}

\author{
Wondu Feyisa Balcha, Azezu Asres Nigussie $\mathbb{D}^{D}$, Fentahun Yenealem Beyene $\mathbb{D}$, \\ and Azimeraw Arega Tesfu
}

Department of Midwifery, College of Medicine and Health Sciences, Bahir Dar University, Bahir Dar, Ethiopia

Correspondence should be addressed to Fentahun Yenealem Beyene; yenefenta84@gmail.com

Received 18 March 2020; Accepted 15 May 2020; Published 1 July 2020

Academic Editor: Marco Scioscia

Copyright (C) 2020 Wondu Feyisa Balcha et al. This is an open access article distributed under the Creative Commons Attribution License, which permits unrestricted use, distribution, and reproduction in any medium, provided the original work is properly cited.

Background. Obstetric fistula is abnormal passageway between the vagina and bladder or rectum, and it has the most devastating effects on physical, social, and economic levels and represents a major public health issue of thousands of women, which failed to provide accessible and appropriate intrapartum care for women within a developing country, particularly in Ethiopia. Therefore, we tried to assess the awareness and its associated factors of obstetrics fistula among pregnant mothers attending antenatal care clinics. Methods. A health institutional-based cross-sectional study was employed from March 4 to 29/2019 among 413 pregnant women. Data was collected by a systematic random sampling technique and entered into a computer using Epi data 3.5, edited and analyzed using Statistical Package of Social Sciences 23.0 version. Bivariate and multivariate logistic regression analyses were employed to estimate the crude and adjusted odds ratio with a confidence interval of $95 \%$ and $p$ value of less than 0.05 considered statically significant. Result. This study identified that 39.5\% with 95\% confidence interval (34.6-44.6\%) of pregnant women had good awareness about obstetrics fistula. Multivariate logistic regression analysis showed that living in urban $[A O R=1.98,95 \% C I=1.07-3.69]$, attending formal education $[A O R=2.11,95 \% C I=1.06-4.12]$, having history antenatal care $[A O R=3.87,95 \% C I=1.60-9.68]$, and childbirth at health institution $[A O R=7.10,95 \% C I=2.52-2.02]$ were significantly associated with awareness of obstetrics fistula. Conclusion and recommendation. This study showed that awareness of obstetrics fistula was low. Residency, education, and occupation of the women, having history of antenatal care and childbirth at health institution was significantly associated with awareness of obstetrics fistula. Still, there is a gap on awareness of obstetrics fistula; therefore, it is good to emphasize on providing information on maternal health care issues, particularly about obstetrics fistula.

\section{Background}

Obstetrics fistula is a complication that arises from prolonged or obstructed labor without prompt medical care which causes tissue necrosis resulting in a hole between the vagina and bladder or rectum, or both [1]. It is a public health issue for women and their communities within developing settings, particularly in Africa and Southeast Asia. Of which signifies a health system that has failed to provide accessible, timely, and appropriate intrapartum care $[2,3]$. Globally, around two million, women living with untreated fistulas, and yearly, there are between 50,000 to 100,000 new cases of OBF develop worldwide. Of these, around 33,000 women live in Sub-Saharan Africa, and it affects about 1.57 per 1,000 women in Sub-Saharan Africa and 1.62 women per 1000 reproductive age in Ethiopia [4]. In prolonged obstructed labor vaginal, bladder, and rectal damage results from compression of the maternal tissue by the fetus during repeated uterine contractions that restrict blood flow, resulting in ischemia and tissue damage and which results in continuous and uncontrolled leakage of urine [5]. OBF primarily affects lower socioeconomic classes, who are under privileged, underemployed, and have limited access to safe delivery attended by qualified health personnel [6]. The underlying factors 
TABLE 1: Percentage distribution of the study participants by socio-demographic characteristics in governmental health facilities of Injibara town, North West Ethiopia, 2019, $(n=413)$.

\begin{tabular}{|c|c|c|c|}
\hline Variables & Categories & Frequency & Percentage \\
\hline \multirow{5}{*}{ Age } & $15-19$ & 24 & 5.8 \\
\hline & $20-25$ & 170 & 41.2 \\
\hline & $26-30$ & 148 & 35.8 \\
\hline & $31-35$ & 45 & 10.9 \\
\hline & $36-40$ & 26 & 6.3 \\
\hline \multirow{3}{*}{ Ethnicity } & Agew & 279 & 67.6 \\
\hline & Amhara & 116 & 28.1 \\
\hline & Others* & 18 & 4.3 \\
\hline \multirow{2}{*}{ Residency } & Urban & 295 & 71.4 \\
\hline & Rural & 118 & 28.6 \\
\hline \multirow{3}{*}{ Religion } & Orthodox & 346 & 83.71 \\
\hline & Muslim & 56 & 3.6 \\
\hline & Protestant & 11 & 2.7 \\
\hline \multirow{2}{*}{ Marital status } & Married & 410 & 99.3 \\
\hline & Single & 3 & 0.7 \\
\hline \multirow{4}{*}{ Educational level of the women } & Not read and write & 108 & 26.2 \\
\hline & Primary school (1-8) & 125 & 30.2 \\
\hline & Secondary school (9-12) & 94 & 22.8 \\
\hline & Diploma and above & 86 & 20.8 \\
\hline \multirow{4}{*}{ Occupational status of the women } & Government employee & 58 & 14.0 \\
\hline & Housewife & 248 & 60.0 \\
\hline & Merchants & 83 & 20.1 \\
\hline & Others $^{* *}$ & 24 & 5.9 \\
\hline \multirow{4}{*}{ Educational levels of the husband $(n=410)$} & Not read and write & 54 & 13.2 \\
\hline & Primary school (1-8) & 115 & 28.1 \\
\hline & Secondary school (9-12) & 99 & 24.1 \\
\hline & Diploma and above & 142 & 34.6 \\
\hline \multirow{6}{*}{ Occupational status of the husband $(n=410)$} & Government employee & 99 & 24.1 \\
\hline & Farmer & 87 & 21.2 \\
\hline & Private organization employee & 40 & 9.8 \\
\hline & Merchants & 146 & 35.6 \\
\hline & Car driver & 23 & 5.6 \\
\hline & Others ${ }^{* * *}$ & 15 & 3.7 \\
\hline
\end{tabular}

* (Oromo and Gumze), ${ }^{* *}$ (student, private organization employee and day laborer), ${ }^{* * *}$ (carpenter and day laborer).

contributing to obstetrics fistula (OBF) include no skilled birth attendants, poor health-seeking behavior, poor referral systems and transportation network, inadequate facilities providing comprehensive obstetric care services, poverty, malnutrition, lack of education, early marriage and childbirth, harmful traditional practices, sexual violence, and lack of good quality or accessible maternal and health care [7-10]. To 2016, Ethiopian Demographic Health Survey (EDHS), the national prevalence of obstetric fistula is less than $1 \%$ among ever-married women. The highest prevalence $(0.7 \%)$ occurs in the Amhara region [11]. OBF is treatable by surgery, by giving palliative care and can be prevented completely through timely access to competent emergency obstetric care as providing support from trained health care professionals throughout pregnancy, use of pantograph in all labor, providing access to family planning, promot- ing birth spacing, and postponing early marriage and by educating the communities and promoting education for girls are the key factors to prevent in long term [2-4, 12]. Therefore, we tried to assess awareness of OBF and its associated factors.

\section{Methods}

2.1. Study Area. The study was carried out in Injibara town which is found in the Southwestern part of the Amhara region and north western part of Ethiopia. The town is located about $447 \mathrm{~km}$ away from the capital city of Ethiopia which is Addis Ababa and $118 \mathrm{~km}$ away from Amhara regional state Bahir Dar city. Injibara is the administrative town of Awi zone. The town has five Kebeles with the 
TABLe 2: Percentage distribution of the study participants by reproductive and obstetrics characteristics in governmental health facilities of Injibara town, North West Ethiopia, $2019(n=413)$.

\begin{tabular}{|c|c|c|c|}
\hline Variables & Categories & Frequency & Percentage \\
\hline \multirow{2}{*}{ Age at first marriage $(n=410)$} & $<18$ & 73 & 17.5 \\
\hline & $>=18$ & 337 & 81.5 \\
\hline \multirow{2}{*}{ Age at first pregnancy } & $<18$ & 43 & 10.4 \\
\hline & $>=18$ & 370 & 89.6 \\
\hline \multirow{2}{*}{ Gravidity } & Primigravida & 148 & 35.8 \\
\hline & Multigravida & 265 & 64.2 \\
\hline \multirow{2}{*}{ Age at first childbirth $(n=252)$} & $<18$ & 25 & 9.92 \\
\hline & $>=18$ & 227 & 90.08 \\
\hline \multirow{2}{*}{ History of abortion $(n=265)$} & Yes & 88 & 33.2 \\
\hline & No & 177 & 66.8 \\
\hline \multirow{2}{*}{ ANC follow-up in previous pregnancy $(\boldsymbol{n}=\mathbf{2 6 5})$} & Yes & 168 & 63.4 \\
\hline & No & 97 & 36.6 \\
\hline \multirow{2}{*}{ Place of delivery for recent childbirth $(\boldsymbol{n}=\mathbf{2 5 2})$} & Health institution & 166 & 65.9 \\
\hline & Home & 86 & 34.1 \\
\hline \multirow{3}{*}{ Mode of delivery for recent childbirth $(\boldsymbol{n}=\mathbf{2 5 2})$} & Spontaneous vaginal delivery & 182 & 72.2 \\
\hline & Instrumental delivery & 45 & 17.1 \\
\hline & Caesarean section delivery & 27 & 10.7 \\
\hline \multirow{3}{*}{ Attendant of the labor $(n=252)$} & Health workers & 166 & 65.9 \\
\hline & TBA & 47 & 18.7 \\
\hline & Family & 39 & 15.4 \\
\hline \multirow{2}{*}{ History of PNC utilization $(\boldsymbol{n}=\mathbf{2 5 2})$} & Yes & 55 & 21.8 \\
\hline & No & 197 & 78.2 \\
\hline \multirow{2}{*}{ History of FP utilization } & Yes & 254 & 61.5 \\
\hline & No & 159 & 38.5 \\
\hline
\end{tabular}

population of 46,745 (23,466 females and 23,279 are males). The town has 2 governmental health facilities [13].

2.1.1. Study Design and Period. A health facility-based crosssectional study was conducted from March 4 to 29/2019 in Injibara town, Awi zone, Ethiopia.

2.1.2. Source of Population. All pregnant women who came to attend ANC at all government health facilities in Injibara town.

2.1.3. Study Population. Pregnant women who attended ANC at selected governmental health facilities in Injibara town.

2.1.4. Inclusive Criteria. Pregnant women who were attended ANC in the governmental health facility at Injibara town.

2.1.5. Exclusive Criteria. Pregnant women who had seriously ill.

2.1.6. Operational Definition. Good awareness: those respondents who scored greater or equal to the mean value questions related to OBF.

Poor awareness: those respondents who scored less than the mean value of the question related to OBF [3].

Obstetrics fistula: obstetrics fistula is an opening in the wall of the vagina connecting to the bladder or rectum due to prolonged or obstructed labor [14].
2.2. Sample Size Determination. The sample size was determined using a single population proportion formula by considering the following assumptions: the proportion of awareness on VVF among pregnant women was $57.8 \%$ [15], 5\% level of significance $(\alpha=0.05)$ and $5 \%$ margin of error $(\omega=0.05)$. The final sample size was adjusted by adding $10 \%$ nonresponse rate thus turned out to be 413 .

2.3. Sampling Procedure and Technique. All governmental health facilities were considering. Information about the client flow to each health facility was obtained from Awi zonal health bureau [16]. The average client flow of the health facilities was taken from a registry book of the health facilities. The number of pregnant women who have attended ANC quarterly in Injibara general hospital was 1320 and in Injibara health center was 2280 . The total sample size was proportionally allocated for each governmental health facility of the town based on their quarterly ANC flow. For each health institution, the first participant selected randomly; then, the subsequent participants were selected by a systematic sampling technique every two interval for each health facility.

2.4. Data Collection Tools and Procedures. A structured interviewer-administered questionnaire was used to collect the data which was adapted from relevant literatures and 
TABLE 3: Distribution of the study participants according to awareness of obstetrics fistula in governmental health facilities of Injibara town, North West Ethiopia, 2019, $(n=413)$.

\begin{tabular}{|c|c|c|c|}
\hline Variables & Categories & Frequency & Percentage \\
\hline \multirow{2}{*}{ Awareness } & Good awareness & 163 & 39.5 \\
\hline & Poor awareness & 250 & 60.5 \\
\hline \multirow{4}{*}{ Source of information } & Media & 65 & 32.5 \\
\hline & Health professional & 80 & 40 \\
\hline & From school & 32 & 16 \\
\hline & Others* & 23 & 11.5 \\
\hline \multirow{2}{*}{ Awareness of OBF risk factors } & Yes & 175 & 42.4 \\
\hline & No & 238 & 57.6 \\
\hline \multirow{8}{*}{ Which risk factors of obstetrics fistula do you know? } & Female gentile mutilation & 121 & 29.3 \\
\hline & Early marriage & 144 & 34.9 \\
\hline & Early pregnancy & 139 & 33.6 \\
\hline & Un spaced childbirth & 86 & 20.8 \\
\hline & Prolonged labor & 137 & 33.2 \\
\hline & Home delivery & 153 & 37.1 \\
\hline & Malnutrition of the mothers & 63 & 15.3 \\
\hline & Not using FP methods & 99 & 24.0 \\
\hline \multirow{2}{*}{ Awareness of symptoms of obstetrics fistula } & Yes & 135 & 32.7 \\
\hline & No & 278 & 67.3 \\
\hline \multirow{3}{*}{ Symptoms of obstetrics fistula } & Urinary incontinency & 134 & 32.5 \\
\hline & Faecal incontinency & 70 & 17.0 \\
\hline & Vulvar irritation & 47 & 11.4 \\
\hline \multirow{2}{*}{ Awareness of availability of obstetrics fistula treatment } & Yes & 92 & 22.3 \\
\hline & No & 321 & 77.7 \\
\hline \multirow{2}{*}{ Awareness of obstetrics fistula prevention } & Yes & 148 & 35.8 \\
\hline & No & 265 & 64.2 \\
\hline
\end{tabular}

* (family and friends).

modified to local context $[3,15]$. Questionnaires were first prepared in the English language; then, it was translated first into Amharic and then to Awigni by an individual who has good ability of these languages then retranslated back to first to Amharic and then too English to check the consistency. The questionnaire was consisting of socio-demographic characteristics, reproductive and obstetrics characteristics, and knowledge and prevention method's related questionnaires (additional file 1). Pretested, structured intervieweradministered questionnaire was used for data collection purposes. The data was collected by two diploma midwives and supervised by two BSc midwives by those who can speak and write the local language.

2.5. Data Quality Assurance. The collected data were checked for the completeness, accuracy, clarity, and consistency after conducting pretest. A pretest was conducted on $5 \%$ or 21 pregnant mothers in one of the health centers out of the study area called Lideta health center, and the instrument was amended accordingly. Any error, ambiguity, or incompleteness identified was corrected immediately. The data collectors were trained for one day about the contents of the questionnaire, methods of data collection, and aim of the study. The data collection process was supervised by the supervisor and the investigator throughout the data collection period.

\section{Data Processing, Analysis, and Interpretation}

Data was coded, cleaned, and entered by Epi. Data version 3.5 and analyzed using computer database software and transported to the SPSS version 23 statistical software. Descriptive statistics like frequencies and percentages were used to present the categorical independent variables, and mean/standard deviation was used to describe a continuous variable. Frequency tables and graphs were used to present descriptive results. For this study, a bivariate logistic regression model was fitted as the most method of analysis. Odds ratios (OR) were computed with the $95 \%$ confidence interval (CI) to see the awareness of OBF for the considered associated factors in this research. Independent factors, with a $P$ value $<0.2$ obtained in the bivariate logistic regression were entered into the multivariate logistic regression models. Consequently, the most important associated factors were identified using the multivariate logistic regression analysis. Then, an adjusted odds ratio (AOR) with $95 \%$ confidence interval was calculated for the most predictive variables, and statistical significance was accepted at $(P<0.05)$. 
TABLE 4: Logistic regression analysis for awareness of obstetrics fistula among study participants in governmental health facilities of Injibara town, North West Ethiopia, 2019.

\begin{tabular}{|c|c|c|c|c|c|c|}
\hline \multirow[t]{2}{*}{ Variables } & \multirow[t]{2}{*}{ Categories } & \multicolumn{2}{|c|}{$\begin{array}{c}\text { Awareness } \\
\text { of OBF }\end{array}$} & \multirow{2}{*}{$\begin{array}{c}\text { Crude OR } \\
(95 \% \text { CI })\end{array}$} & \multirow{2}{*}{$\begin{array}{l}\text { Adjusted OR } \\
\quad(95 \% \mathrm{CI})\end{array}$} & \multirow[t]{2}{*}{$\boldsymbol{P}$ value } \\
\hline & & Yes & No & & & \\
\hline \multirow{4}{*}{ Age } & $15-19$ & 6 & 18 & 1 & 1 & \\
\hline & $20-25$ & 82 & 88 & $2.80(1.06-7.39)$ & $2.75(0.98-7.68)$ & 0.054 \\
\hline & $26-30$ & 62 & 86 & $2.17(0.81-5.76)$ & $2.68(0.86-8.36)$ & 0.088 \\
\hline & $>=31$ & 13 & 58 & $0.67(0.22-2.03)$ & $1.12(0.29-4.31)$ & 0.870 \\
\hline \multirow{2}{*}{ Residency } & Rural & 20 & 98 & 1 & 1 & \\
\hline & Urban & 143 & 152 & $4.61(2.71-7.85)$ & $1.98(1.07-3.69)$ & 0.030 \\
\hline \multirow{2}{*}{ Educational level of the women } & No-formal education & 17 & 91 & 1 & 1 & \\
\hline & Attended formal education & 146 & 159 & $4.92(2.80,8.65)$ & $2.11(1.06,4.12)$ & 0.034 \\
\hline \multirow{2}{*}{ Age at first marriage } & $<18$ & 14 & 59 & 1 & 1 & \\
\hline & $>=18$ & 148 & 189 & $3.30(1.77-6.14)$ & $1.02(0.43-2.40)$ & 0.973 \\
\hline Age at first & $<18$ & 8 & 35 & 1 & 1 & \\
\hline Pregnancy & $>=18$ & 155 & 215 & $3.15(1.42-6.99)$ & $0.93(0.26-.3 .35)$ & 0.914 \\
\hline \multirow{2}{*}{ Have ANC in previous pregnancy } & No & 9 & 88 & 1 & 1 & \\
\hline & Yes & 82 & 86 & $9.3(4.41-19.73)$ & $3.87(1.60-9.38)$ & 0.003 \\
\hline \multirow{2}{*}{ Place of delivery } & Home & 5 & 81 & 1 & 1 & \\
\hline & Health institution & 82 & 84 & $15.8(6.10-41.02)$ & $7.10(2.52-20.02)$ & $<0.001$ \\
\hline \multirow{2}{*}{ Previous postnatal care } & No & 54 & 143 & 1 & & \\
\hline & Yes & 33 & 22 & $3.97(2.13-7.41)$ & $1.34(0.61-2.91)$ & 0.467 \\
\hline \multirow{2}{*}{ FP utilization } & No & & 116 & 1 & 1 & \\
\hline & Yes & & 134 & $2.42(1.56-3.71)$ & $1.13(0.65-1.97)$ & 0.677 \\
\hline
\end{tabular}

\section{Result}

4.1. Socio-Demographic Characteristics of the Respondents. A total of 413 women participated in the study with a response rate of $100 \%$. The mean age of the study participants was 26.60 years with $( \pm S D=5.072)$ and ranging from 15 to 40 years. About $41.2 \%$ were found in the age group 20-25 years. Around $67.6 \%$ of participants were Agew ethnicity, and $83.7 \%$ were orthodox Christianity religion followers. Of the study participants, $60 \%$ were housewives. From the participants, 30.2\% attended primary school, and $34.6 \%$ husbands of the respondents had diploma and above educational levels (Table 1).

4.2. Obstetrics Characteristics of the Study Participants. From the total participants, $81.5 \%$ were married at the age of greater than eighteen, and $89.6 \%$ of them were got pregnant first at the age of greater than eighteen with the median age of 20 years. With parity of the total participants, $39.0 \%$ of the participants' were nulliparous. Among multipara, $66.8 \%$ had no history of abortion, and $63.4 \%$ had a history of ANC follow-up in their previous pregnancy. Among those who had a history of birth, $65.9 \%$ were given their most recent childbirth at a health facility (Table 2).

4.3. Current Awareness of Obstetrics Fistula. In this study, 163 (39.5\%) of the participants had good awareness about OBF. The risk factors, symptoms of OBF, and availability of OBF treatment and prevention methods identified by 175
(42.4\%), 135 (32.7\%), 92 (22.3\%), and 148 (35.8\%) of the participants, respectively (Table 3 ).

4.4. Determinants of A wareness of Obstetrics Fistula. Bivariate analysis was done to assess any relation between independent variables and awareness of obstetrics fistula. In bivariate analysis, age, residency, education status of the respondents, age at first marriage, age at first pregnancy, parity, history of ANC, place of delivery, utilization of PNC, and utilization of modern FP were considered statistically significant with awareness of obstetrics fistula. Multivariable logistic regression analysis showed that participants who live in urban were 1.98 times more likely aware of OBF than who lives in rural $(A O R=1.98,95 \% C I=1.07-3.69)$. Likewise, respondents who attend formal education were 2.11 times more likely aware of OBF than those who did not attend $(A O R=2.11$, $95 \% C I=1.406-4.12)$. Respondents who had history of ANC follow-up were 3.87 times more likely aware of OBF than those who had no history of ANC follow-up $(A O R=3.87,95 \%$ $C I=1.60-9.38$ ), and those who gave birth in health institution were 7.10 times more likely aware of OBF than who gave birth at home $(A O R=7.10,95 \% C I=2.52-20.02)$ (Table 4$)$.

\section{Discussion}

In this study, less than half (39.5\%) with $95 \%$ of $(C I=34.6-44.6 \%)$ of the participants had good awareness about OBF. This result was lower than studies in Northern Ghana, Nigeria, and Tanzania $(45.8 \%, 57.8 \%$, and $60.1 \%)$ 
$[17,18,15]$, respectively. The difference might be the difference in the study population, study design, and the difference in socio-demographic characteristics. The awareness levels in this study is in line with a study in Burkina Faso (36.4\%) [3]. The closeness of this result might be due to as both studies done in developing country and may have related level of awareness. The figure in this study is in line with 2016; EDHS (39\%) were reported as they had heard about OBF at national levels [12]. This closeness of the result might be due to the same socio-demographic characteristic of the respondents and may be due to closeness of the study period. In this study, socio-demographic and obstetric factors were related to awareness of OBF. The odds of having awareness about OBF was higher among respondents who are living in urban were approximately two times higher than who are lives in rural $(A O R=1.98,95 \% C I=1.07-3.69)$. This finding agree with a study done in Burkina Faso where urban residency was more aware of OBF than rural residency [3]. This might be due to urban women with more availability of information access, easily accessibility of facility, and accessibility of education than rural women. The odds of having awareness about OBF was higher among respondents who attend formal education were two times higher than who did not attend formal education $(A O R=2.11,95 \% C I=1.06-4.12]$. The finding in this study agree with to studies done in Burkina Faso and Northern Ghana [3, 17]. This might be those attending formal education have greater opportunity to get information, asking and getting health services than those who had not attended formal education. The odds of having awareness about OBF was higher among study participants who had history of ANC follow-up in their previous pregnancy were approximately four times higher than who had not had ANC follow-up in their previous pregnancy $(A O R=3.87,95 \% C I=1.60-9.38)$. This might be attributed to that utilization of maternal health care services have greater opportunity to get exposed to health education and to dissemination structured and targeted message on the health of women and utilization of ANC services may help them to get information about OBF. In this study, awareness about OBF was higher among study participants who had gave birth at health institution were seven times higher than those who gave birth at home $(A O R=7.10,95 \% C I=2.52$ -20.02). This might be that women who had history of maternal and health care services utilization would have high chance of getting information from health personnel in the form of health education or counseling about OBF.

\section{Conclusion and Recommendation}

In this study, pregnant women who had good awareness about OBF were lower than a study done in Nigeria. Residency, educational levels of the respondents, having history of ANC, and place of delivery were having positive association with awareness of OBF. While occupational levels of the respondents have negative association with awareness of OBF. As per finding, improving the level of awareness, by promoting women's education, full utilization of both ANC and intrapartum care, and creating different strategies for rural women, gives a better understanding of $\mathrm{MNCH}$ ser- vices. We also recommend further researcher to come up with additional and detailed findings especially on qualitative aspect.

\section{Abbreviations \\ ANC: Antenatal care \\ EDHS: Ethiopian Demography Health Survey \\ FP: $\quad$ Family planning \\ OBF: Obstetrics fistula \\ VVF: Vesico vaginal fistula.}

\section{Data Availability}

The data used to support the findings of this study are available from the corresponding author upon request.

\section{Ethical Approval}

Ethical clearance was obtained from the institutional review board of Bahir Dar University. A formal letter request of cooperation was written to the Injibara health office. Written consent was obtained from each study participant for those ages greater than 16 years and from parents for those ages less than 16 years. Confidentiality of information and privacy was maintained.

\section{Conflicts of Interest}

The authors declare that they have no conflict of interests regarding the publication of this paper.

\section{Authors' Contributions}

WF AN and FB inception designed the protocol, data analysis, interpretation, manuscript drafting, wrote the paper, and revised the manuscript. WF and AT participated in the data collection, the editorial, and data entry and analysis. All authors read and approved the final paper.

\section{Acknowledgments}

We are highly thankful to the College of Medicine and Health Sciences, Bahir Dar University, for sponsoring the research project. We would like to extend our thanks to the Injibara town Health Office for permitting to conduct the study and providing the necessary preliminary information. We would also like to extend our appreciation to the study participants, supervisors, and data collectors.

\section{References}

[1] L. de Bernis, "Obstetric fistula: guiding principles for clinical management and programme development, a new WHO guideline," International Journal of Gynecology \& Obstetrics, vol. 99, no. S1, pp. S117-S121, 2007.

[2] Ö. Tunçalp, V. Tripathi, E. Landry, C. K. Stanton, and S. Ahmed, "Measuring the incidence and prevalence of obstetric fistula: approaches, needs and recommendations," Bulletin of the World Health Organization, vol. 93, no. 1, pp. 60-62, 2015. 
[3] A. O. Banke-Thomas, S. F. Kouraogo, A. Siribie, H. B. Taddese, and J. E. Mueller, "Knowledge of obstetric fistula prevention amongst young women in urban and rural Burkina Faso: a cross-sectional study," PLoS One, vol. 8, no. 12, article e85921, 2013.

[4] World Health Organization2014, https://www.who.int/ reproductivehealth/topics/maternal_perinatal/fistula/en/.

[5] T. J. I. P. Raassen, E. G. G. Verdaasdonk, and M. E. Vierhout, "Prospective results after first-time surgery for obstetric fistulas in East African women," International Urogynecology Journal, vol. 19, no. 1, pp. 73-79, 2007.

[6] L. L. Wall, "Obstetric fistula is a "neglected tropical disease"," PLoS Neglected Tropical Diseases, vol. 6, no. 8, article e1769, 2012.

[7] A. Velez, K. Ramsey, and K. Tell, "The Campaign to End Fistula: What have we learned? Findings of facility and community needs assessments," International Journal of Gynecology \& Obstetrics, vol. 99, no. S1, pp. S143-S150, 2007.

[8] F. Donnay and K. Ramsey, "Eliminating obstetric fistula: progress in partnerships," International Journal of Gynecology \& Obstetrics, vol. 94, no. 3, pp. 254-261, 2016.

[9] T. Capes, C. Ascher-Walsh, I. Abdoulaye, and M. Brodman, "Obstetric fistula in low and middle income countries," Mount Sinai Journal of Medicine: A Journal of Translational and Personalized Medicine, vol. 78, no. 3, pp. 352-361, 2011.

[10] S. Miller, F. Lester, M. Webster, and B. Cowan, "Obstetric fistula: a preventable tragedy," Journal of Midwifery \& Women's Health, vol. 50, no. 4, pp. 286-294, 2005.

[11] I. CSACE, E. Demographic, and H. Survey, Addis Ababa, Ethiopia, and Rockville, CSA and ICF, Maryland, USA, 2016.

[12] M. L. Polan, A. Sleemi, M. M. Bedane, S. Lozo, and M. A. Morgan, "Obstetric fistula," in Essential Surgery: Disease Control Priorities, Third Edition (Volume 1)The International Bank for Reconstruction and Development/The World Bank.

[13] Central Statistical Service of Ethiopia, 2007 Population and Housing Census: Administrative Report, 2007.

[14] A. J. Adler, S. Fox, O. M. R. Campbell, and H. Kuper, “Obstetric fistula in southern Sudan: situational analysis and key informant method to estimate prevalence," BMC Pregnancy and Childbirth, vol. 13, no. 1, 2013.

[15] P. O. Ezeonu, K. C. Ekwedigwe, M. E. Isikhuemen et al., "Awareness of obstetric vesicovaginal fistula among pregnant women in a rural hospital," Advances in Reproductive Sciences, vol. 5, no. 3, pp. 39-46, 2017.

[16] Awi Zone Health Bureau, Awi Zone Health Bureau Annual plan Achievement Report, Ethiopia Google Scholar, 2015.

[17] M. F. Saeed, A. Alhassan, K. Opare-Asamoah, and C. Kuubiere, "A survey on obstetric fistula awareness in Northern Ghana," European Journal of Experimental Biology, vol. 4, no. 4, pp. 178-182, 2014.

[18] M. Kazaura, R. Kamazima, and E. Mangi, "Perceived causes of obstetric fistulae from rural southern Tanzania," African Health Sciences, vol. 11, no. 3, 2011. 